\title{
Mathematical Modeling of Diurnal Patterns of Turbulent Heat Fluxes using Modified Aerodynamic Resistance Method
}

\author{
R. T. Akinnubi ${ }^{1, *}$, O. O. Oketayo ${ }^{2}$, B. F. Akinwale ${ }^{1}$, M. O. Ojo ${ }^{1}$ and A. Ikusika ${ }^{1}$ \\ ${ }^{1}$ Department of Physics, 'Adeyemi College of Education \\ Ondo, Nigeria \\ ${ }^{2}$ Department of Physics, Federal University Oye-Ekitii \\ Ekiti State, Nigeria \\ ${ }^{*}$ Corresponding author's email: rufus782000 [AT] yahoo.com
}

\begin{abstract}
The development of improved methods for estimating turbulent heat fluxes is important in effective monitoring of the surface energy balance for climate change prediction. However, different parameterized models carried out at the local site of Nigerian Micrometeorological site (NIMEX-1) did not consider the surface heat fluxesaerodynamics resistance relationships, and these validated models cannot be incorporated into the Climate models because some of the input climate variables are not routinely available in some meteorological stations. This study therefore, aims at improving the diurnal patterns of surface heat fluxes estimates using radiometric surface temperature and aerodynamic surface-layer resistances. Hourly data of air temperature $\left(T_{a}\right)$, soil temperature $\left(T_{\text {soil }}\right)$, global radiation $\left(Q_{L}\right)$, surface temperature $\left(T_{s}\right)$, wind speed $(u), Q_{H}$ and $Q_{E}$ were obtained from the NIMEX-1 at Ile-Ife $\left(7.55^{\circ} N, 4.55\right.$ ${ }^{\circ} E$ ). The $Q_{H}$ and $Q_{E}$ were estimated using Aerodynamic Resistance Approach algorithm which was modified to reduce the large bias errors between the aerodynamic temperature and surface temperature above the ground level. The algorithms were validated and rated using the following error statistics: coefficient of determination $\left(r^{2}\right)$, Mean Bias Error (MBE) and Root Mean Square Error (RMSE). The RMSE and MBE for the modeled $Q_{E}$ estimated using ARM and MAR reduced from $28.33 \mathrm{Wm}^{-2}$ to $14.33 \mathrm{Wm}^{-2}$ and 36.93 to $10.74 \mathrm{Wm}^{-2}$ respectively while for $Q_{H}$, the RMSE and MBE reduced from $17.29 \mathrm{Wm}^{-2}$ to $9.49 \mathrm{Wm}^{-2}$ and 31.39 to $16.93 \mathrm{Wm}^{-2}$ respectively. The $r^{2}$ values ranged from 0.68 to 0.73 and 0.95 to 0.98 for $Q_{H}$ and $Q_{E}$ respectively. The MAR had the highest $r^{2}$ and least error values. Hence, the proposed modified Aerodynamic resistance models are estimated the diurnal and seasonal turbulent heat fluxes accurately for tropical regions.
\end{abstract}

Keywords--- Surface energy balance, aerodynamics surface layer resistances, radiometric surface temperature, Mean bias error

\section{INTRODUCTION}

The genesis and evolution of earth's climate is largely regulated by global energy balance. The turbulent heat fluxes are the major components of the energy balance and these surface heat fluxes are very essential in estimation of evapotranspiration and monitoring surface energy budget. In West Africa, several studies have explored several profile parameterization methodologies to estimate these heat fluxes using the measured data (Mauder et al., 2007; Oladosu and Jegede, 2005; Ayoola et al., 2006; Balogun et al., 2004; Akinnubi and Adeniyi, 2010; Adeniyi and Otunla, 2010) but these methodologies do not tacitly consider the aspect of aerodynamic surface layer resistance, radiometric surface temperature and excess resistance in the estimation of above mentioned heat fluxes. Empirical models like Bowen Ratio method, Modified Bowen Ratio method and Flux-variance model have been used and validated, but they cannot be incorporated into the Climate models because some of the input climate variables are not routinely available in some meteorological stations. The bulk Aerodynamic Resistance Method (ARM) is usually incorporated into Atmospheric Global Circulation Models (AGCM) and other regional models to estimate surface heat fluxes and evaporation (Koloskov et al., 2007; Sun et al., 2006; Niclos et al., 2009). The ARM model usually expresses fluxes in terms of transfer coefficients over various exchange pathways such as aerodynamic or surface resistances which compensate for the large temperature difference that occur between surface temperature $\left(T_{s}\right)$ and the air temperature $\left(T_{a}\right)$ and require specification of the vertical temperature difference between surface temperature and the air temperature (Ma et al., 2002; Su et al., 1998; Su et al., 1999; Ma et al., 2000; Van den Hurk, 2001; Su, 2002; Jia, 2004).

Over the years, this model has been implemented and validated using experimental data for semi-arid regions. Nagar et al., 1995 used the aerodynamic resistance method to estimate sensible heat and latent heat flux from arid regions. Wu and Wang (2005) used the resistance based evaporation coefficient method to estimate evaporation from soil surfaces. Voogt and Grimmond (2000) used the resistance model to estimate sensible and latent heat fluxes over different heterogeneous landscapes. Mafouf and Noilhan (1991) compared bulk aerodynamic formulation of five different forms to 
estimate evaporation from bare soil. Ma et al. (2010) implemented and validated the resistance model for regional estimations of sensible and latent heat fluxes over Tibetan Plateau with a heterogeneous landscape. Carine and Parlov (2012) compared the turbulent heat fluxes estimated using the resistance model with eddy covariance data. They obtained errors ranging from $25.61 \mathrm{Wm}^{-2}$ to $78.82 \mathrm{Wm}^{-2}$ for sensible heat fluxes and $12.08 \mathrm{Wm}^{-2}$ to $23.77 \mathrm{Wm}^{-2}$ for latent heat fluxes. Nonetheless, studies revealed that fairly good results were achieved when compared with a measured data. However, other studies reported large uncertainties and error in the results. To the best of our knowledge the resistance model is yet to be validated for this region. And this is due to lack of measured micrometeorological data. However, in recent years, direct measurements of turbulent heat fluxes using eddy covariance method are available at the Nigerian Micrometeorological Experiment site. The estimates of these surface heat fluxes at a time interval of interest require the knowledge of the values of some climate variables such as air temperature, radiometric surface temperature and wind speeds at the same or similar time intervals. However, weather stations do not always provide standard data at time of interest. Thus, diurnal changes in these variables need to be calculated from available daily average values using meteorological models. The objective of this work is to model the diurnal patterns of turbulent heat fluxes using available meteorological variables for stations where such data are not available.

\section{MATERIALS AND METHODS}

The data collection was carried out in the period between February 24 and March $10^{\text {th }}, 2004$ as part of NIMEX-1 Project during an intensive field campaign. The campaign involved the use of homogenous flat surface and different sensors for characterizing the state of the atmosphere and the soil physical characteristics. However, the mean and turbulent micrometeorological parameters in the surface layer were measured for duration of the NIMEX-1 project. Two meteorological masts were set up for profile measurements of the wind, temperature, atmospheric radiation, and the soil (sub-surface) parameters while a third was devoted for eddy covariance measurements of the turbulent fluxes.An eddy covariance system consisting of an ultrasonic anemometer together with a Krypton hygrometer placed on a 2 m mast was integrated to measure the turbulent fluxes. The combined arrangement will produce the turbulent wind, acoustic temperature and humidity components. The sonic turbulence parameters were sampled at a frequency of $16 \mathrm{~Hz}(\mathrm{Jegede} e t$ al., 2004;Fokenet al., 2006).

\subsection{Modified aerodynamic resistance model (mar)}

The Aerodynamic Resistance Model (ARM) treats the whole surface as a single source of heat flux transported to the overlying atmosphere (Castellviet al., 2006). The single-source model estimate sensible and latent heat fluxes using surface temperature while it does not considering the difference between $z_{0 h}$ and $z_{0 m}\left(\kappa B^{-1}=0\right)$.

$$
\begin{aligned}
Q_{H}^{A R M} & =\frac{\rho c_{p}\left(T_{s}-T_{a}\right)}{r_{a}} \\
Q_{E}^{A R M} & =\frac{\rho c_{p}\left(e\left(T_{s}\right)-e_{a}\right)}{\gamma\left(r_{a}\right)}
\end{aligned}
$$

Where $r_{a}$ is estimated from the modified Louis model (Akinnubi and Adeniyi, 2017 a).Based on the fact that the direct use of the radiometric temperature to evaluate the surface heat fluxes causes large error when the $T_{s}-T_{a}$ is very large. It becomes problem is particularly in the case of a bare soil with evidence of growing short grasses. It has shown that the use of original resistance equation generally overestimates the sensible heat flux as well as latent heat fluxes (Stewart et al., 1989; Voogt and Grimmond, 2000). A preliminary analysis also confirmed that the difference between surface temperature and air temperature was very large $\left(T_{s}-T_{a}>20^{\circ} \mathrm{C}\right.$ for unstable condition; $T_{s}-T_{a}>15^{\circ} \mathrm{C}$ for stable condition) and under such conditions the original resistance model performs poorly. However, observations confirm that the use of the sum of aerodynamic resistance and excess resistance (as proposed many authors) to compensate for large difference in bulk models was not enough (Ma et al., 2002 b; Jia, 2004). This difference must be corrected by a term proportional to the temperature difference between the surface and air temperature. The model assumed that $\mathrm{z}_{0 \mathrm{~h}}$ is not equal to $\mathrm{z}_{0 \mathrm{~m}}$ and the excess resistance was taken into account in the estimation of surface heat fluxes.

$$
Q_{H}=\frac{\rho C_{p}\left(T_{s}-T_{a}\right)}{r_{a}+r_{b}}
$$

The equation above shows that sensible heat flux is not proportional to temperature difference between surface and the air temperature.

$$
\begin{gathered}
\text { The Sensible heat } \\
Q_{H}=\frac{\rho C_{p}\left(T_{s}-T_{a}-c \delta T\right)}{r_{a}+r_{b}}
\end{gathered}
$$$$
\text { flux }
$$$$
\text { can }
$$$$
\text { be }
$$$$
\text { rewritten }
$$

c being defined by 
$c=[1 / 1+x]$ with $x=\frac{r_{s}}{r_{a}} 5$

Consequently, a procedure was developed to account for $\delta T$ without additional measurement. This procedure is based upon the proposal that $\delta T$ has to increase with the temperature difference between the soil surface and the air $\left(T_{s}-T_{a}\right)$. In the current experiment the soil was sandy loam at $5 \mathrm{~cm}$ and the surface layer dries slowly gently after a rain event, thus $\delta T$ tends to increase when net radiation and the surface temperature increase. It was assumed that $\delta T$ and the temperature difference between $\left(T_{s}-T_{a}\right)$ were linked by following relationship.

$$
\delta T=\beta\left(T_{s}-T_{a}\right)^{m}
$$

$\mathrm{m}$ being a positive integer as $\beta$ a real positive real number. Recent literature show that $\beta$ is estimated

$$
\beta=\frac{T_{\text {aero }}-T_{a}}{T_{s}-T_{a}}
$$

where $T_{\text {aero }}$ is the aerodynamic surface temperature. This temperature is defined as the temperature at the height of roughness length for heat. Unlike roughness length for momentum, where the surface wind speed reduces to zero due to surface friction, roughness length for heat is the level heat transfer at zero. The aerodynamic temperature falls between surface air and radiometric skin temperature, but can be quite different from the latter. The $T_{\text {aero }}$ has been expressed as

$$
T_{\text {aero }}=0.17\left(T_{s}-T_{a}\right)^{-\mathrm{z}_{0 \mathrm{~m}} / \mathrm{z}_{0 \mathrm{~h}}}
$$

To determine the value of $\beta$ and $\mathrm{m}$, the best fit is obtained from the empirical relationship when one of the variables is fixed (Table 1 ). When $\mathrm{m}$ is fixed, a linear regression is obtained to determine the value of $\beta$. $\beta$ is the slope between $T_{a e r o}-$ $T_{a}$ and $T_{s}-T_{a}$

$$
T_{\text {aero }}-T_{a}=\beta\left(T_{s}-T_{a}\right)+c
$$

The values of $\beta$ vary for 0.2 to 1 . But in this work, however $\mathrm{c}=0$ is assigned, which is justified by the fact that the value of $T_{s}-T_{a}$ will be fairly extrapolated to the original point of the co-ordinate. To determine the value of $\mathrm{m}$, when $\beta$ is fixed. The linear expression of eqn. becomes

$$
T_{\text {aero }}-T_{a}=\left(T_{s}-T_{a}\right)^{m}
$$

Transforming the expression into logarithm form,

$\log \left(T_{\text {aero }}-T_{a}\right)=m \log \left(T_{s}-T_{a}\right)$

For estimating latent heat flux from radiometric surface temperature $T_{s}$, it has been shown that a simple Ohm law type formulation based on a typical one-layer model does not work. The one-layer model together with statistical relationship has proved to give satisfactory estimation of sensible heat flux using NIMEX-1 data.

$$
Q_{E}^{M A R}=\frac{\rho c_{p}\left(e\left(T_{a e r o}\right)-e_{a}-e(c \delta T)\right.}{\gamma\left(r_{a}+r_{b}\right)}
$$

Table 1: Determination of parameter $\beta$ and $m$ of eqn. (11) by fitting to equation to observed data of surface temperature by linear fraction of $T_{\text {aero }}-T_{a}=\beta\left(T_{s}-T_{a}\right)+c$ and $\log \left(T_{\text {aero }}-T_{a}\right)=m \log \left(T_{s}-T_{a}\right)+c$ respectively. $r^{2}$ and $\sigma$ are coefficient of determination and standard error of residual.

\begin{tabular}{llllllll}
\hline $\boldsymbol{\beta}$ & $\mathbf{r}^{\mathbf{2}}$ & $\boldsymbol{\sigma}$ & Equation & $\mathbf{m}$ & $\mathbf{r}^{\mathbf{2}}$ & $\boldsymbol{\sigma}$ & Equation \\
\hline 0.20 & 0.42 & 1.21 & $\mathrm{Y}=1.4 \mathrm{X}+7.0$ & 0.20 & 0.22 & 0.97 & $\mathrm{Y}=0.2 \mathrm{X}+0.54$ \\
0.40 & 0.62 & 0.72 & $\mathrm{Y}=0.4 \mathrm{X}+1.67$ & 0.40 & 0.35 & 0.77 & $\mathrm{Y}=0.4 \mathrm{X}+0.3$ \\
0.60 & 0.82 & 0.40 & $\mathrm{Y}=0.6 \mathrm{X}+1.97$ & 0.60 & 0.63 & 0.64 & $\mathrm{Y}=0.6 \mathrm{X}+0.74$ \\
0.80 & 0.85 & 0.20 & $\mathrm{Y}=0.8 \mathrm{X}-4.95$ & 0.80 & 0.65 & 0.44 & $\mathrm{Y}=0.8 \mathrm{X}-0.10$ \\
1.00 & 0.91 & 0.04 & $\mathrm{Y}=\mathrm{X}-7.95$ & 1.00 & 0.71 & 0.37 & $\mathrm{Y}=\mathrm{X}-0.34$ \\
0.47 & 0.99 & 0.01 & $\mathrm{Y}=0.47 \mathrm{X}$ & 0.71 & 0.99 & 0.10 & $\mathrm{Y}=0.71 \mathrm{X}$ \\
\hline
\end{tabular}




\section{$2.4 \quad$ Statistical analysis}

To evaluate the efficiency of the approaches, their results are compared with the measured data set using statistical means. The Mean Bias Error (MBE) and Root Mean Square Error (RMSE) were calculated as

$$
\begin{aligned}
& M B E=\sum_{i=0}^{n} \frac{\left(r_{a}(\text { estimated })-r_{a}(\text { reference data })\right.}{n} \\
& R M S E=\sqrt{\sum_{i=0}^{n} \frac{\left(r_{a}(\text { estimated })-r_{a}(\text { reference data })\right)^{2}}{n}}
\end{aligned}
$$

where $\mathrm{n}$ is the number of observation.

where $\mathrm{n}$ is the number of observation and $\mathrm{p}$ is the number of predictor variables. The software packages used for the study were Origin and SPSS.

\section{RESULT AND DISCUSSION}

\subsection{Determination of parameter $m$ and $\beta$ for the statistical relationship linking $\delta T$ to $T_{s}-T_{a}$ in the resistance equation.}

The values of $\mathrm{m}$ and $\beta$ for which the best fit was obtained between $T_{a e r o}-T_{a}$ and $\left(T_{s}-T_{a}\right)$ are shown in Figure 1 and 2. Since $\mathrm{m}$ was fixed, $\beta$ varies from 0.20 to 1.00 with a step of 0.01 and the value retained was that which minimized the standard mean error (with highest $r^{2}$ value). It is clear that the best fit obtained for $\beta$ was 0.47 , with minimum error of 0.01 i.e. for a linear function linking $\delta T$. The corresponding value of $\mathrm{m}$ with lowest error was 0.71 . Thus we can infer that resistance equation with $\beta=0.47$ and $\mathrm{m}=0.71$ representing a good estimate of $\delta T$, this is valid for the entire experiment work for the site. The values of $\beta$ and m obtained were lower (by the order of 0.10 ) than the results obtained for a vegetated surface is reported Lhomme andElguero, (1999) and Kustas et al. (2008). But in this work, however c $=0$ is assigned, which is justified by the fact that the value of $T_{s}-T_{a}$ will be fairly extrapolated to the original point of the co-ordinate as shown Fig. 2. The relationship between the measured Bowen ratio $\beta$ and the radiation Bowen ratio $\beta_{\text {est }}$ was empirically adjusted for the 14 days of measurement (DOY 55-DOY 70) by means of a least square regression in the form $\beta_{E c}=a+$ $b \beta_{\text {est }}$. This result shows an excellent behaviour for the whole data set (Fig.1). The value of the parameter obtained were intercept $\mathrm{a}=0.02$ and slope $\mathrm{b}=0.99$ with a coefficient of determinate $r^{2}=0.97$ and a minimum standard deviation 0.02 . According to these results, an empirical method for estimating the Bowen ratio has been proposed as

$\beta_{\text {est }}=0.02+0.99 \beta_{s}$

\subsection{Diurnal cases}

The composite diurnal variation of the modeled $Q_{H}$ against the measured $Q_{H}$ for ARM and MAR in Fig. 3 for wet and dry periods. The modeled $Q_{H}$ was slightly overestimated by about $30-50 \mathrm{Wm}^{-2}$ during the early hours of the morning and $20 \mathrm{Wm}^{-2}$ to $50 \mathrm{Wm}^{-2}$ during the late hours of the day. The modeled $Q_{H}$ showed a slight underestimation during the mid-day for wet period. For dry period, the modeled ARM $Q_{H}$ was grossly overestimated during the mid-days (about 80 $100 \mathrm{Wm}^{-2}$ ) and late hours of the night by $70-80 \mathrm{Wm}^{-2}$. The modeled MAR $Q_{H}$ showed a better performance for wet and dry periods. Though, slight underestimation of about $10 \mathrm{Wm}^{-2}$ to $12 \mathrm{Wm}^{-2}$ was observed for early hours and mid-day during wet days. The MAR modeled $Q_{H}$ almost approximated the measured $Q_{H}$ during the dry days, this implies that for $Q_{H}$ favoured dry days than wet days.In Fig 4,the ARM modeled $Q_{H}$ showed a larger overestimation of about $80-100 \mathrm{Wm}^{-2}$ for wet period and $100-150 \mathrm{Wm}^{-2}$ during the dry for mid days and late hours of the night. There was little or no underestimation and overestimation during the dry period.it could be said that the MAR favours the simulation of $Q_{E}$ than $Q_{H}$ in a tropical area. In Fig. 5 and 6, the RMSE and MBE reduced from $28.33 \mathrm{Wm}^{-2}$ to $14.33 \mathrm{Wm}^{-2}$ and 36.93 to 10.74 $\mathrm{Wm}^{-2}$ respectively for $Q_{H}$. For $Q_{H}$ the RMSE and MBE reduced from $17.29 \mathrm{Wm}^{-2}$ to $9.49 \mathrm{Wm}^{-2}$ and 31.39 to $16.93 \mathrm{Wm}^{-2}$ respectively. The $r^{2}$ values for ARM and MAR ranged from 0.68 to 0.73 and 0.95 to 0.98 for $Q_{H}$ and $Q_{E}$ respectively. The MAR had the highest $r^{2}$ and least error values. The $Q_{E}$ estimated by MAR models were about $5 \mathrm{Wm}^{-2}$ higher than the one estimated by Oladosu and Jegede (2005) using Bowen ratio method. Also, the relatively good agreement between $Q_{E}$ estimated by corrected resistance equation was consistent with previous results reported by Balogunet al. (2004), who found agreement between instantaneous $Q_{E}$ determined by Bowen ratio system and $Q_{E}$ estimated by eddy correlation system. 


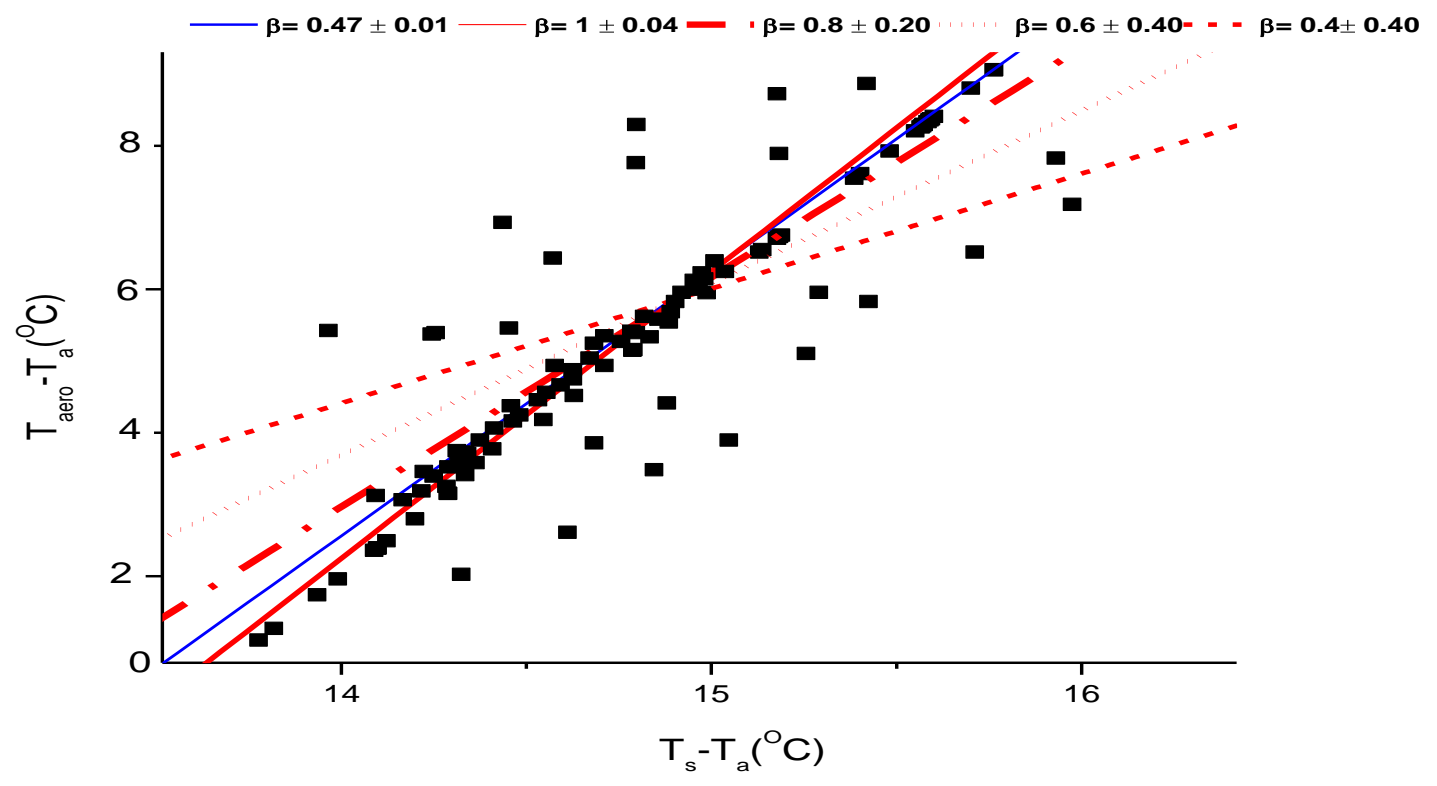

1: The fitted lines for different values of $\beta$ using the linear relationsip between between $T_{a e r o}-T_{a}$ and $\left(T_{s}-T_{a}\right)$.

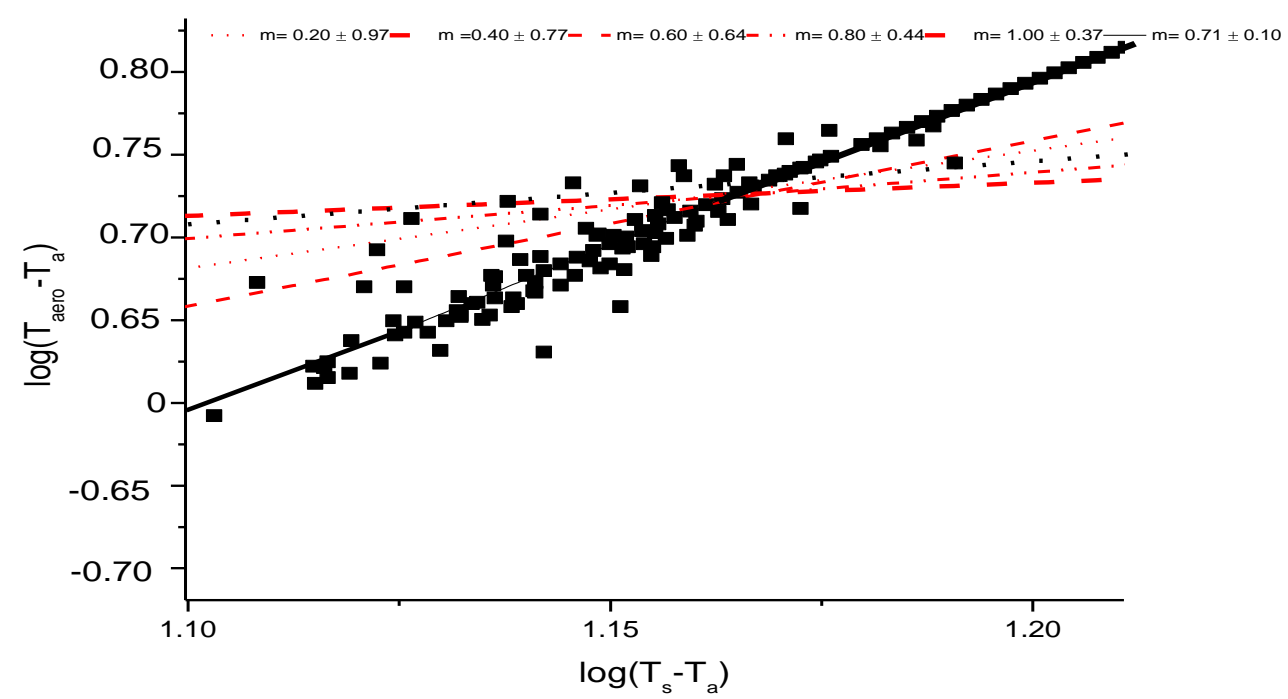

Figure 2: The fitted lines for different values of $m$ using the linear-log relationship between $T_{a e r o}-T_{a}$ and $\left(T_{s}-T_{a}\right)$. 


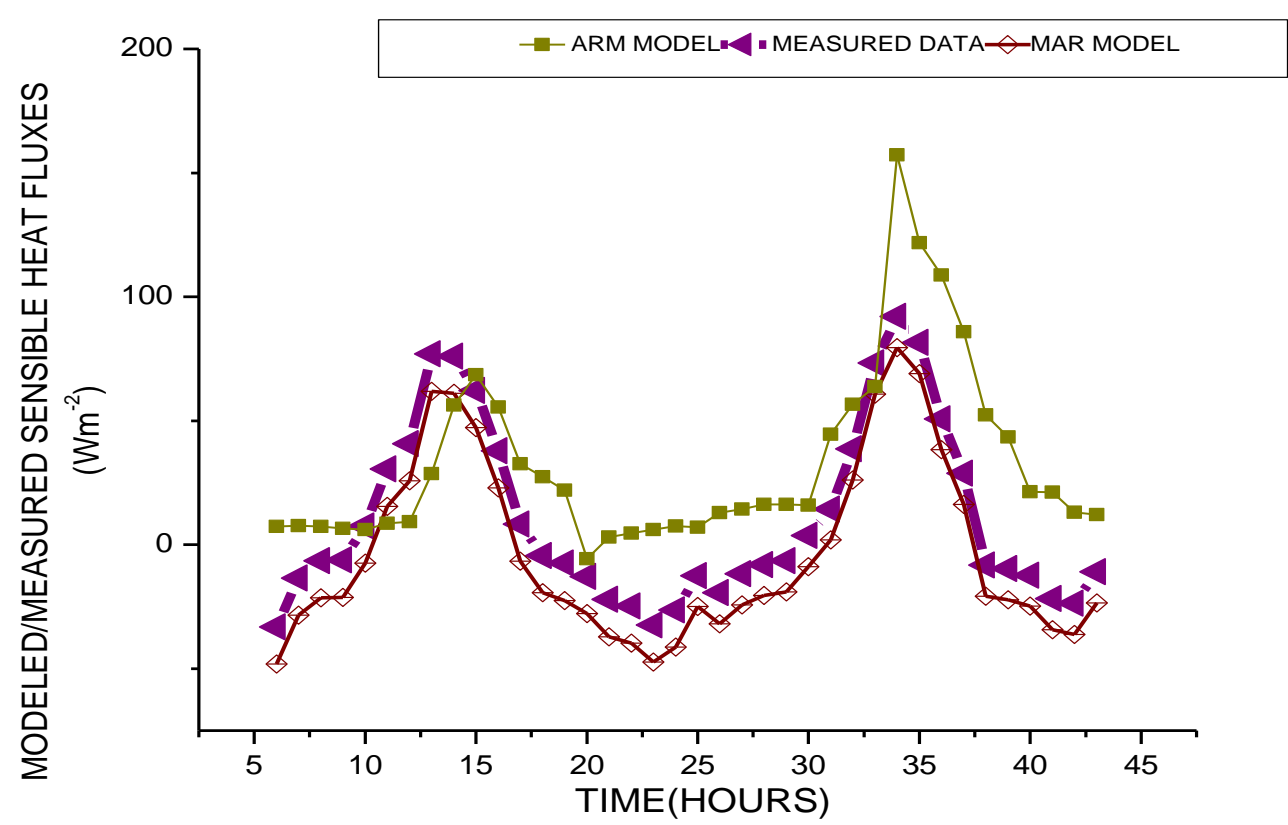

Figure

3: Comparison between the composite diurnal variation of measured $\mathrm{Q}_{\mathrm{H}}\left(\mathrm{Wm}^{-2}\right)$ and modeled values for wet and dry periods.

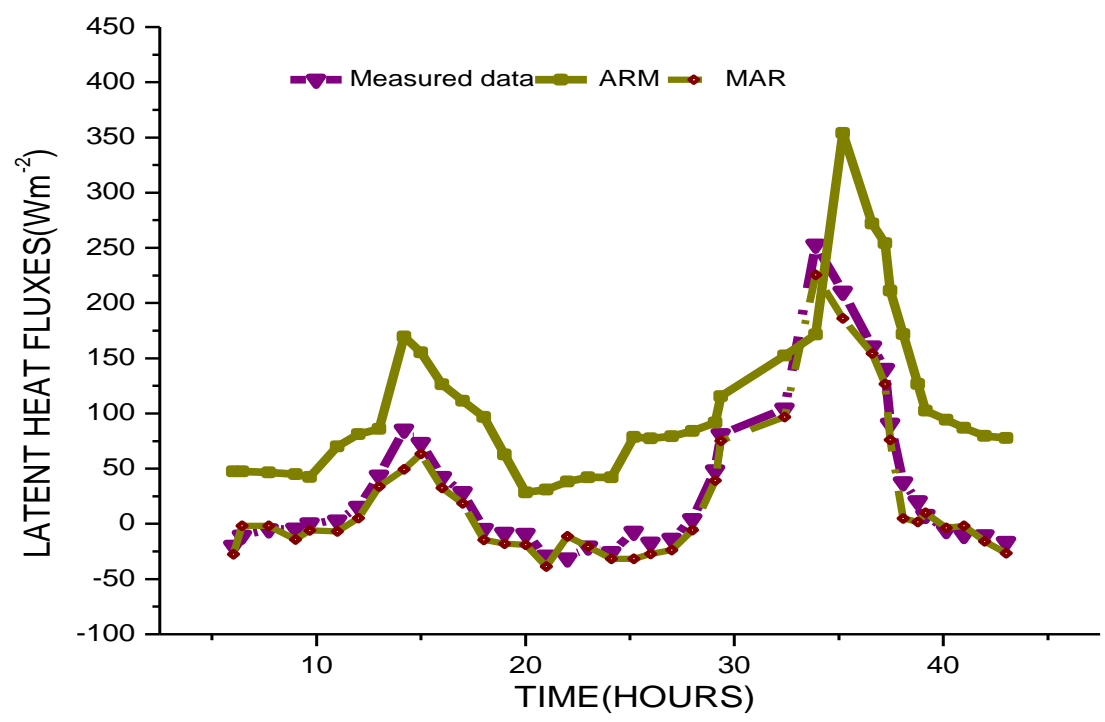

Figure 4: Comparison between the composite diurnal variations of measured $\mathrm{Q}_{\mathrm{E}}\left(\mathrm{Wm}^{-2}\right)$ and modeled values for wet and dry periods. 

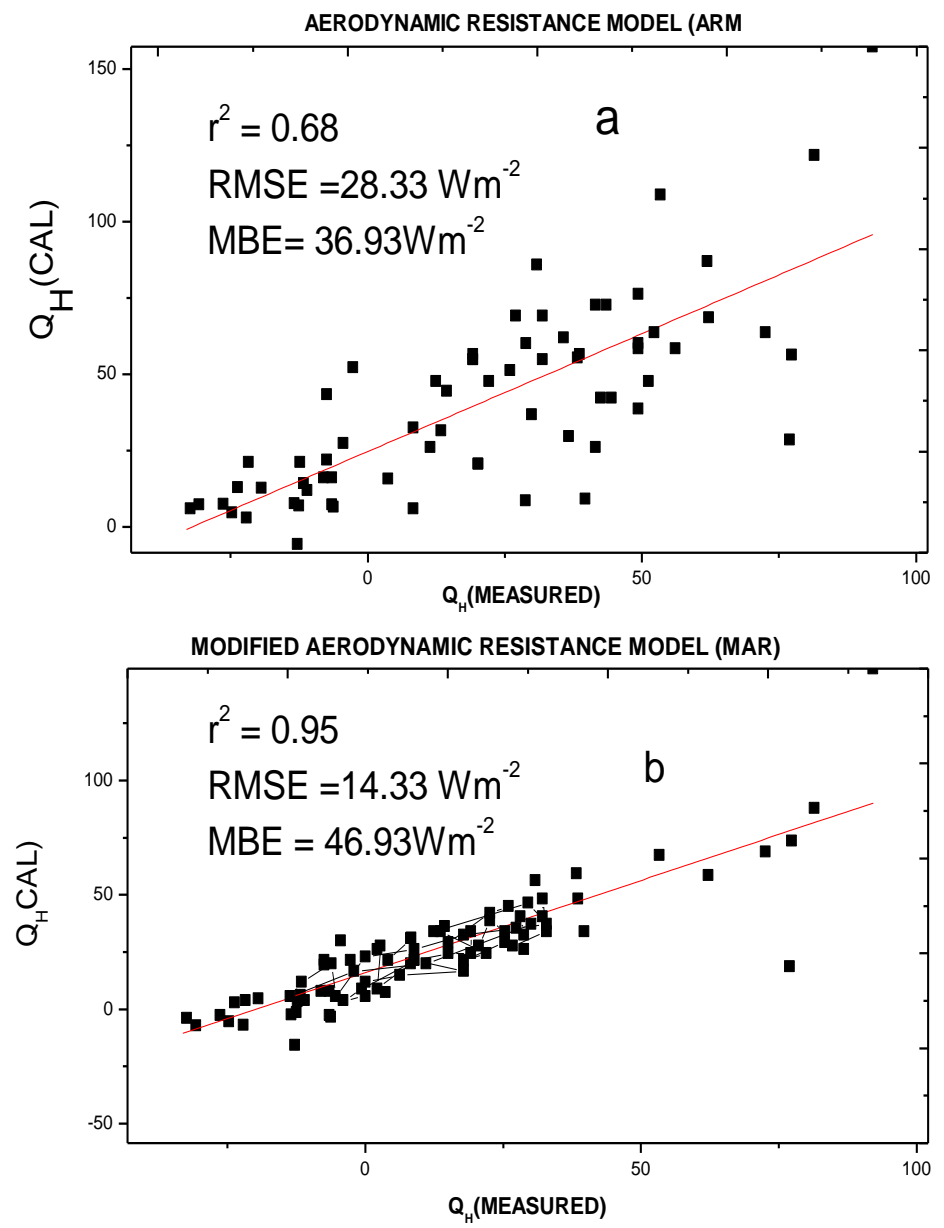

Figure 5: Scatter plots showing Modeled $\mathrm{Q}_{\mathrm{HV}}$ measured $\mathrm{Q}_{\mathrm{H}}$ forDOY 55-70, 2004. 


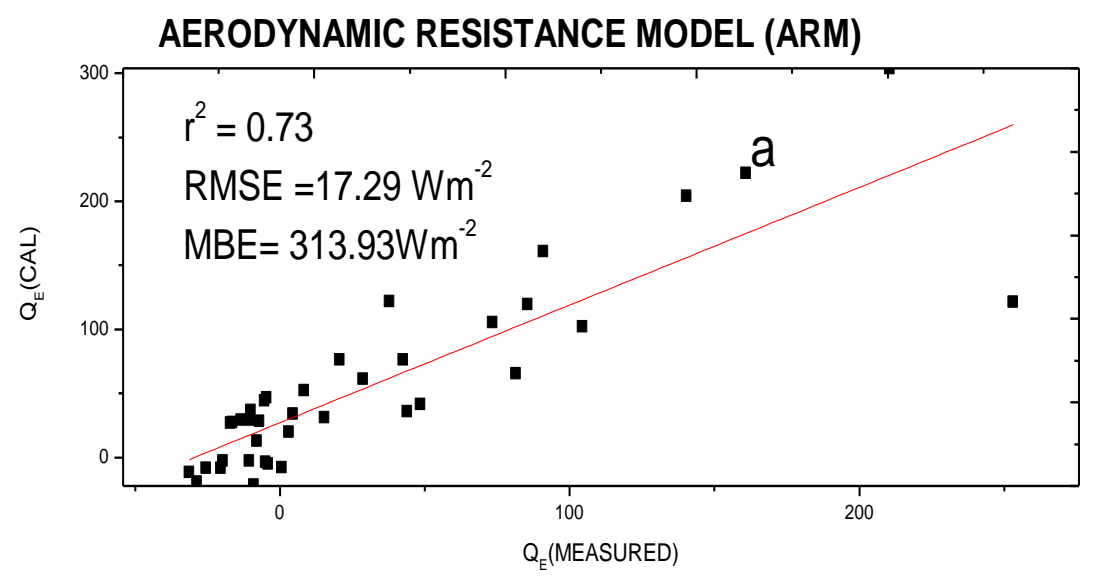

MODIFIED AERODYNAMIC RESISTANCE MODEL (MAR)

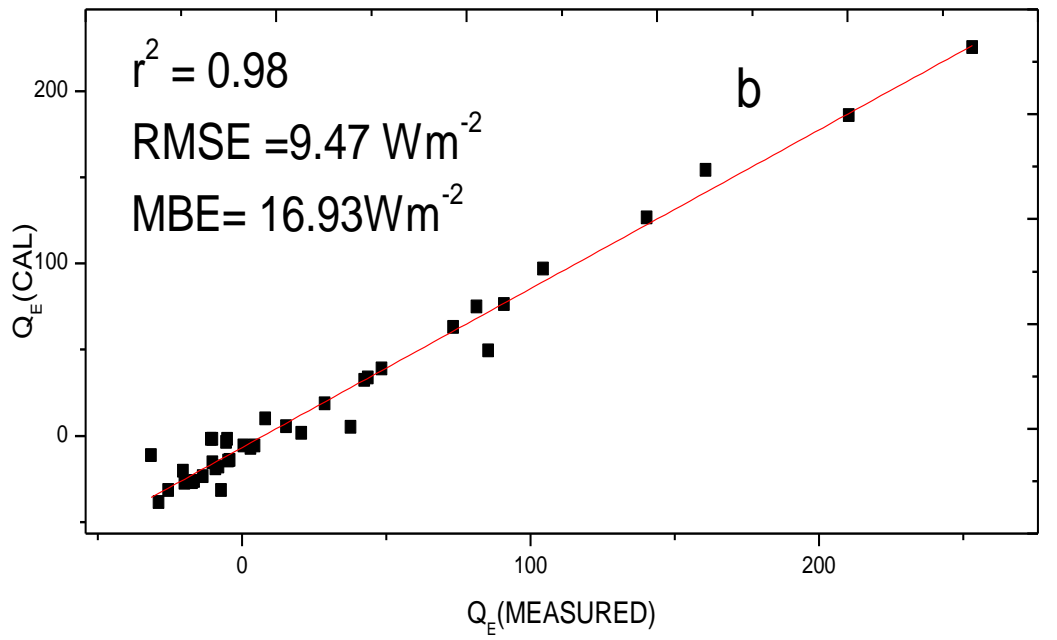

Figure 6: Scatter plots showing Modeled QE vs measured QE for DOY 55-70, 2004 


\section{CONCLUSION}

The performance of Modified Aerodynamic Resistance model was critically evaluated to model the diurnal pattern of turbulent heat fluxes from the available routine meteorological data. The estimated land surface heat fluxes from the proposed resistance parameterization methodologies were consistent with the ground measurements while their relative errors were less than $10 \%$. This makes the proposed resistance model very reliable to estimate the diurnal and seasonal turbulent heat fluxes accurately for tropical regions.

\section{REFERENCES}

[1 ]Akinnubi, R. T. and Adeniyi, M.O "Investigation of the surface energy budget at Nimex_3 site, Ibadan, using Bowen ratio energy balance method". International Journal of Engineering and Mathematical Intelligence, 3, pp 1-3, (2010).

[2] Akinnubi. R. T and Adeniyi M.O "The Parameterization of Humid Tropical Surface-Layer Aerodynamic Resistance to Heat Transfer using Modified Louis Scheme", Transaction of of Nigeria Association of Mathematical Physics,. 3(2), pp 395-398, (2017).

[3] Ayoola, M. A. Olatona. G. I. and Oladiran.E. O. The March 29, "Solar Eclipse As Observed At Ibadan, Nigeria". paper Presented At NIP 30th Annual Conference, (2006).

[4] Balogun, A. A., Jegede, O. O., Aregbesola, E. O., Ogolo, A. E., Ohamobi, S. and Sunmonu, K. E, "Evaluation of some surface layer characteristics during NIMEX-1. Paper presented at the Workshop on the Nigerian micrometeorological experiment (NIMEX-1)" Obafemi Awolowo University, Ile-Ife, Nigeria. 22nd, 2004 (2004):

[5] Castellvi, F. Martínez-Cob A., Pérez-Coveta, O "Estimating sensible and latent heat fluxes over rice using surface renewal. Agric Forest Meteorol., 139: pp 164-169, (2006).

[6] Foken, T., Wimmer, F., Mauder, M., Thomas, C., and Liebethal, C (2006). Some aspects of the Environmental Impact Assessment, International Centre for Theoretical Physics, Trieste, June 1990.

[7] Jegede, O. O., Okogbue, E. C., and Balogun, E. E. "Proceedings of the workshop and the Nigeria Micrometeorological experiment (NIMEX-1)" July, 15, 2004, Ile-Ife, Nigeria. Comfort Press and Publishing Co. Lagos, Nigeria, pp 66, (2004).

[8] Jia, L. "Modeling heat exchanges at land-atmosphere interface using multi-angular thermal infrared measurements" PhD Thesis, Wageningen University, pp 199, (2004).

[9] Koloskov G., Mukhamejonav K.H., Tanto T.W Monin-Abukhov "Length as a cornerstone of the SEBAL calculations of evapotranspiration". Journal of Hydrology, 10, (2007)

[10] Kustas, W.P., Hatfield, J.L. and J.H. Prueger. "The soil moisture-coupling experiment (SMACEX): background, hydrometeorological conditions, and preliminary findings" J. Remote Sens. Environ., 74, pp 327-342, (2008).

[11] Lhomme J.P. and E. Elguero, "Examination of evaporative fraction diurnal behaviour using a soil-vegetation model coupled with a mixed-layer model” Hydrol. Earth. Syst. Sci., 3 (2), pp 259-270, (1999).

[12] Ma, Y., O. Tsukamoto, H. Ishikawa, Z. Su, M. Menenti, Wang, J., and Wen. J. "Determination of Regional land surface heat flux densities over heterogeneous landscape of HEIFE Integrating satellite remote sensing with field observations" Journal of Meteorological Society of Japan, 803, pp 485-501, (2002).

[13] Ma, Y., O. Tsukamoto, X. Wu, I. Tamagawa, J. Wang, H. Ishikawa, Z. Hu, and H. Gao, “Characteristics of energy transfer and micrometeorology in the surface layer", (2000).

[14] Mafouf, J. F., and J. Noilhan. (1991). Comparative study of various formulations of evaporation from bare soil using in situ data. J. Appl. Meteor., $30,1354-1365$

[15] Mauder, M., Jegede, O. O., Okogbue, E. C., Wimmer, F., and Foken, T "Surface energy balance measurement at a tropical site in West Africa during the transition from dry to wet season”, Theor. Appl. Climatol., 89, pp 171-183, (2007).

[16] Nagar, S. G., Sectoramayya, Tyagi. A and Siingh. S. S. Estimation of daytime surface fluxes of radiation and heat at Anand during 13 - 17 May 1997. Current Science, 83 , pp $39-46$, (1995).

[17] Niclòs, R., Estrela, M.J., Valiente, J.A., Barberà, M.J “Clasificación periódica de coberturas terrestresaescala regional con imágenes MODIS”. GeoFocus, 10, pp 1-17, (2009).

[18] Oladosu, O R and Jegede, O.O “Thermal properties of an agricultural site in Ile- Ife, Nigeria” Nigeria J. Pure Appl. Phy. 4(1), pp 71-74, (2005).

[19] Stewart, J.B., Shuttleworth WJ, Blyth K, Lloyd CR: "FIFE: a comparison between aerodynamic surface temperature and surface radiometric temperature over sparse prairie grass” 19th Conf. Agric Forest Meteorol, Charleston, South Carolina, March 1989, pp 144-146,(1989).

[19] Su, Z. "The Surface Energy Balance System SEBS for estimation of turbulent heat fluxes” Hydrology and Earth System Sciences, 61, pp 85-99, (2002)

[20] Su, Z., and Menenti M. "Mesoscale Climate Hydrology: The contribution of the new observing systems" Pre-Execution Phase, Final Report, BCRS NUSP-2, 99-05, pp 14, (1999). 
[21] Su, Z., M. Menenti, H. Pelgrum, B. J. Van den Hurk J. M., and Bastiaanssen W. G. M.. "Remote sensing of land surface heat fluxes for updating numerical weather predictions", In Nieuwenhuis, G.J.A., Vaughan, R.A., and Molenaar, M.eds, Operational Remote Sensing for Sustainable Development, Balkema, pp 393-402, (1998).

[23]Sun, Y.-J., Wang, J.-F., Zhang, R.-H., Gillies, R.R., Xue, Y., Bo, Y.-C. "Air temperature retrieval from remote sensing data based on thermodynamics. Theory" Appl. Climatol., 80, pp 37-48, (2006).

[24] Van den Hurk, B. J. J. M., (2001) “Energy balance based surface flux estimation from satellite Boundary-Layer” Meteorol. 82, pp 119-134.

[25] Voogt, J. A. and Grimmond, C. S. B. "Modelling Surface Sensible Heat Flux Using Surface Radiative Temperatures in a Simple Urban Area" Journal of Applied Meteorology, 39, pp 1679-1699 (2000).

[26] Wu, J., Wang, D. (2005) "Estimating evaporation coefficient during two stage evaporation from soil surfaces” Soil Sci. 170, pp 235-243. 